\title{
Relationship between physical and cognitive performance in community dwelling, ethnically diverse older adults: a cross- sectional study
}

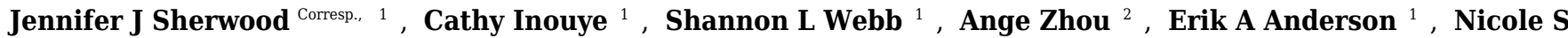 \\ Spink ${ }^{1}$ \\ 1 Department of Kinesiology, California State University, East Bay, Hayward, California, United States \\ 2 Department of Statistics and Biostatistics, California State University, East Bay, Hayward, California, United States \\ Corresponding Author: Jennifer J Sherwood \\ Email address: jennifer.sherwood@csueastbay.edu
}

Background. Regular exercise training stimulates physiological adaptations to improve physical performance, reduce chronic disease risk, and slow age-related cognitive decline. Since the physiological mechanisms responsible for aging-associated cognitive decline are not yet fully understood, and traininginduced physiological adaptations responsible for performance measure improvements are specific to the type (aerobic vs. strength) and intensity of training, studies are needed to assess the relationships between physical performance measures and cognitive performance in older adults. These results could be used to guide exercise prescriptions with the goal of improving age-related cognitive performance. The purpose of this study was to investigate the relationship between physical performance measures and cognitive performance in a population of community dwelling, ethnically diverse older adults.

Methods. The cognitive performance of ninety independent, community dwelling participants (69 female, 21 male), aged $75 \pm 9.5$ years (mean \pm SD) was measured with the Modified Mini-Mental State Test (3MS), Trailmaking Tests A and B (TMT A \& B), and the Animal Naming test. Sociodemographic (age, sex, ethnicity, medication use, years of education) and anthropometric data were collected, physical activity was assessed with the Physical Activity Scale for the Elderly (PASE), peak hand-grip strength, distance walked in the 6MWT, and heart rate pre-, during, and up to 5 min. post- 6MWT were measured. Forward stepwise multiple regression analyses were performed with each cognitive measure as a dependent variable.

Results and Discussion. Controlling for sociodemographic covariates, peak heart rate during the 6MWT (6MWT HR $R_{\text {PEAK }}$ ) was positively correlated with performance in the 3MS ( $\left.p<0.017\right)$, and TMT A $(p<0.001)$ and $B(p<0.029)$. Controlling for sociodemographic covariates, PASE was positively $(p=0.001)$, and $\beta$ blocker use negatively ( $p=0.035)$, correlated with performance on the Animal Naming test. Also, controlling for sociodemographic covariates, PASE was positively correlated with performance on the TMT $A(p=0.017)$. Here we show that higher peak heart rate during the 6MWT is positively correlated with cognitive performance in a population of community dwelling, ethnically diverse older adults (ages 60-95 years).

Conclusion. Higher peak heart rate during the 6MWT was found to be independently and positively correlated with cognitive function in community-dwelling older adults. Although additional work is needed, these results are promising and suggest that physicians, exercise professionals, and/or fitness/fall prevention programs may use peak heart rate during the 6MWT to easily monitor exercise intensity to support cognitive health. 
1 Relationship between physical and cognitive performance in community dwelling, ethnically diverse older adults: a cross- sectional study

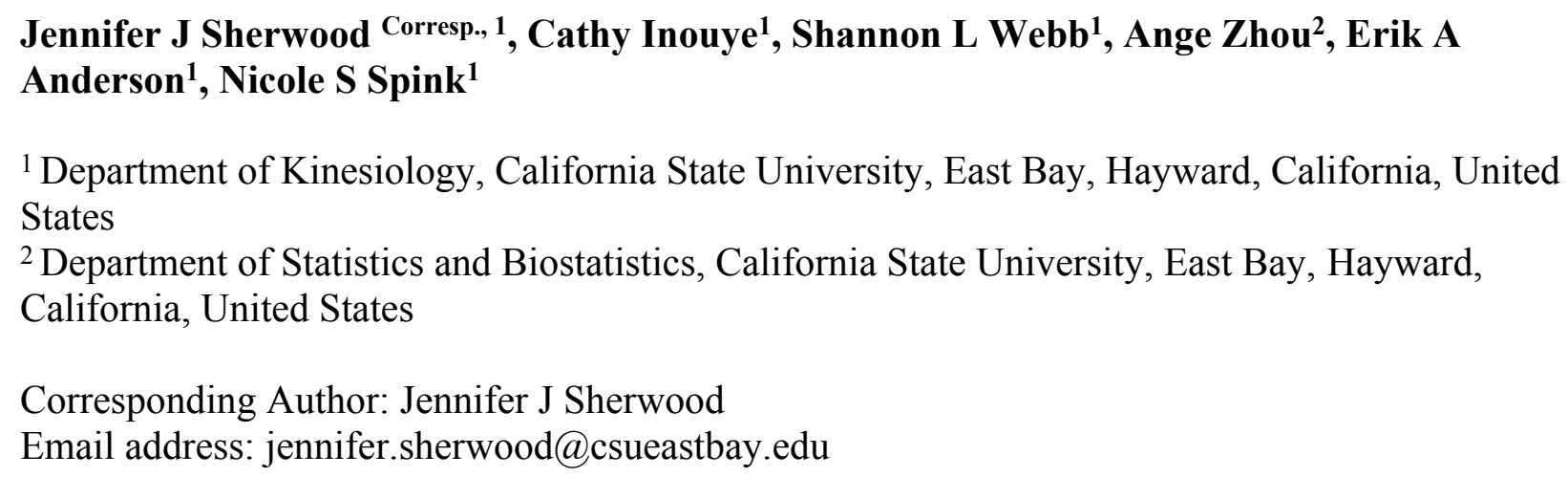

Methods. The cognitive performance of ninety independent, community dwelling participants (69 female, 21 male), aged $75 \pm 9.5$ years (mean \pm SD) was measured with the Modified MiniMental State Test (3MS), Trailmaking Tests A and B (TMT A \& B), and the Animal Naming test. Sociodemographic (age, sex, ethnicity, medication use, yrs. of education) and anthropometric data were collected, physical activity was assessed with the Physical Activity Scale for the Elderly (PASE), peak hand-grip strength, distance walked in the 6MWT, and heart rate pre-, during, and up to $5 \mathrm{~min}$. post- 6MWT were measured. Forward stepwise multiple regression analyses were performed with each cognitive measure as a dependent variable.

Results and Discussion. Controlling for sociodemographic covariates, peak heart rate during the

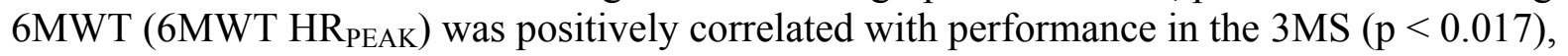
and TMT A $(p<0.001)$ and B $(p<0.029)$. Controlling for sociodemographic covariates, PASE was positively $(p=0.001)$, and $\beta$-blocker use negatively $(p=0.035)$, correlated with performance on the Animal Naming test. Also, controlling for sociodemographic covariates, PASE was positively correlated with performance on the TMT A $(p=0.017)$. Here we show that higher peak heart rate during the 6MWT is positively correlated with cognitive performance in a population of community dwelling, ethnically diverse older adults (ages 60-95 years).

Conclusion. Higher peak heart rate during the 6MWT was found to be independently and positively correlated with cognitive function in community-dwelling older adults. Although additional work is needed, these results are promising and suggest that physicians, exercise 
49 professionals, and/or fitness/fall prevention programs may use peak heart rate during the 6MWT 50 to easily monitor exercise intensity to support cognitive health.

51 
52 Introduction

53 Approximately 5.4 million people, or $\sim 22 \%$ of the population aged 71 years (yrs.) and older in

54 the United States are affected by cognitive impairment without dementia (Plassman et al., 2008).

55 Age-related chronic diseases such as hypertension and cardiovascular disease (Ylikoski et al., 56 2000), chronic atrial fibrillation (Farina et al., 1997), and diabetes (Desmond, Tatemichi, Paik, \& 57 Stern, 1993) are associated with impaired cognitive function. Although encouraging evidence 58 suggests that regular physical activity reduces the risk of age-related chronic disease and slows 59 cognitive decline (Bherer, Erickson,\& Liu-Ambrose, 2013; Kirk-Sanchez \& McGough, 2014; 60 Tarumi et al., 2013; Barnes, Yaffe, Satariano, \& Tager, 2003), evidence is lacking to prescribe 61 physical activity to benefit cognitive function beyond 'be active'. Since training-induced 62 physiological adaptations responsible for improving physical performance measures are specific 63 to the type (aerobic vs. strength), intensity, and duration of training, studies are needed to resolve 64 the relationship between specific physical performance measures and cognitive performance in 65 older adults. These results could be used to guide exercise prescriptions with the goal of 66 67 improving cognitive performance. In addition, regular physical training improves health and the ease of performing daily physical activities.

In older adults, the ability to perform activities of daily living (ADL) correlates with performance in the 6MWT (Enright et al., 2003), a test generally well-tolerated by older adults (>68 yrs. old). The 6MWT is an exercise test in which individuals are encouraged to cover as much distance as possible at a self-selected pace, and is a measure of cardiovascular fitness and

72 functional capacity (Rikli \& Jones, 1998); functional capacity is the integrated responses of all

73 the systems involved during exercise, including the pulmonary and cardiovascular systems, 74 systemic circulation, peripheral circulation, blood, neuromuscular system, and muscle 75 metabolism.

76 Positive associations between functional capacity and cognitive performance have been reported 77 in cross-sectional studies of healthy older adults (Matthé, Roberson, \& Netz, 2015; Lord \& 78 Menz, 2002), but the physiological mechanisms responsible for aging-associated cognitive 79 decline are not yet fully understood. Some studies reporting a relationship between functional 80 capacity and cognitive performance have found that this relationship disappears after controlling 81 for demographic covariates such as age (Lord \& Menz, 2002) while other studies report that this 82 relationship remains. In a cross-sectional study of 80 outpatients with stable chronic heart failure 
83 (72.4 \pm 6.2$)$ yrs.; mean \pm SD), Baldasseroni et al., (2010) found a positive association between 84 distance walked in the 6MWT and overall global cognitive function assessed in the Mini Mental 85 State Examination even after adjusting for demographic covariates, indexes of chronic heart 86 failure severity, comorbidities, level of disability, and quality of life.

87 Higher hand-grip strength, an assessment of muscular fitness (Roberts et al., 2011), has also been 88 associated with better age-related cognitive function (Alfaro-Acha et al., 2006; Taekema,

89 Guessekloo, Maier, Westendorp, \& de Craen, 2010) and self-reported measures of physical 90 activity (Eggermont, Milberg, Lipsitz, Scherder, \& Leveille, 2009). A longitudinal study of cognitively healthy older adults found that a higher composite measure of muscular strength was associated with a slower rate of cognitive decline (Boyle et al., 2009) and more specifically, maximal hand-grip strength measures have been associated with better age-related cognitive function (Alfaro-Acha et al., 2006; Taekema et al., 2010). Intervention studies report that a 16 and 9 week strength training program (Moul, Goldman, \& Warren , 1995; Ozkaya et al., 2005) resulted in improvements to cognition, proposed mechanism being earlier sensory processing and attention to external stimuli found in the strength as compared to endurance trained group (Ozkaya et al., 2005).

In addition to the broader dimensional aspects of exercise programs, e.g., cardiovascular vs. strength training, exercise intensity is a key component of physical training programs (Cress et al., 2005). Physical activity (PA) performed at a higher intensity may benefit cognitive function (Angevaren et al., 2007) as has been demonstrated in longitudinal (Abbott et al., 2004; Laurin, Verreault, Lindsay, MacPherson, \& Rockwood, 2001; Van Gelder, et al., 2004) and crosssectional works (Hogan, Mata, \& Carstensen, 2013). In 2257 men aged 71 - 93 yrs., higher intensity walking ( $>3 \mathrm{~m}$ in less than $3 \mathrm{sec}$ ) at a baseline measure was associated with lowered risk of dementia assessed three and six years later (Abbott et al., 2004), and high intensity PA was associated with less cognitive loss in women ( $>65$ yrs.) over 5 years (Laurin et al., 2001). Also, low-moderate intensity PA in older men followed for 10 years was found to be associated with cognitive benefits, and cognitive decline was greater in those men whose PA intensity declined over the study period (Van Gelder, et al., 2004). Previous studies have linked distance walked during the 6MWT to cognitive function (Matthé et al., 2015; Lord \& Menz, 2002; Baldasseroni et al., 2010), but the relationship between exercise intensity during the 6MWT and cognitive performance has not been studied. 
114 Guidelines for monitoring exercise intensity in older adults often prescribe exercise as a 115 percentage of maximal oxygen uptake $\left(\mathrm{VO}_{2 \mathrm{max}}\right)$, percentage of heart rate reserve, Borg Rating of 116 Perceived Exertion (RPE), or Metabolic Equivalent of Task (MET) (Chodzko-Zajko et al., 2009;

117 Nelson et al., 2007; Warburton, Nicol, \& Bredin, 2006). For ease of use in a field test, such as 118 the 6MWT, RPE and MET stand to be good candidates although some problems exist with 119 application of these tests in older populations. For example, although RPE is often used as a 120 monitoring technique, a deconditioned state and a prescribed intensity of $\mathrm{VO}_{2 \max }$ may limit its 121 accuracy (Grange et al., 2004; Dunbar \& Kalinski, 2004). Additionally, direct measures of 122 resting metabolic rates in older adults were $2.6 \mathrm{ml} \cdot \mathrm{kg}^{-1} \cdot \mathrm{min}^{-1}, 31.6 \%$ lower than the resting 123 metabolic standard of $3.5 \mathrm{ml} \cdot \mathrm{kg}^{-1} \cdot \mathrm{min}^{-1}$ normally used when calculating METs. This had the 124 effect of elevating MET levels during walking conditions when $\mathrm{VO}_{2}$ measures were being taken 125 (Hall et al., 2013). Although distance covered is the primary recorded measure during the 126 6MWT, the additional use of heart rate measures provides an easily obtained and objective 127 method to monitor exercise intensity during the test.

128 The Physical Activity Scale for the Elderly, a self-reported index of physical activity, has also 129 been reported to be associated with cognitive function in a large sample of 600 older participants 130 recruited from a longitudinal cohort even when regression models were further adjusted for 131 cardiovascular disease risk factors (Eggermont et al., 2009). This activity scale is a short survey 132 that has been validated in the older population, is easily scored, and represents a composite 133 physical activity score representing household, occupational, and recreational/exercise activities 134 over a one-week period (Washburn et al., 1993).

135 Experimental approach to the problem:

136 The rationale for this study is as follows: considering the relationship between PA and cognitive 137 performance in older adults, and the unique relationship between performance on physical 138 measures and the type, intensity, and duration of PA, our research objective was to assess the 139 relationships between physical and cognitive performance in community dwelling, ethnically 140 diverse, older adults. Since sociodemographic factors are likely to moderate these relationships, 141 multivariate analyses were used to tease out these complex relationships.

142 Using a cross-sectional approach, stepwise multiple regression analyses were performed to 143 determine which physical measure best explained performance in each of the 4 dependent 144 variables (different model for each response variable): 3MS, Trailmaking A \& B, and Animal 
145 Naming test. This study suggests that peak heart rate in the 6MWT may be used to predict 146 cognitive status.

\section{Materials \& Methods}

148 Participants were volunteers recruited via word-of mouth, flyers, and e-mail announcements

149 from fitness/fall prevention programs at independent-living senior dwellings and local 150 community senior centers, and from the general population at California State University, East 151 Bay (CSUEB). To be included in this study, participants had to be between the ages of 60-95 152 yrs., nonsmokers, ambulatory (without the use of an assistive device), able to communicate 153 (speak and read) English, and could not have uncontrolled cardiac, pulmonary, or metabolic 154 illnesses that would contraindicate submaximal exercise testing according to guidelines 155 established by the American College of Sports Medicine (ACSM) (Reibe et al., 2015). In this 156 exploratory study, the primary objective was to determine which physical performance test best 157 correlates with cognitive performance. Sample size was based on feasibility. Study methods and 158 procedures were approved by the Institutional Review Board at CSUEB (\#2014-231-F).

159 Participants signed an informed consent for study participation and completed written 160 questionnaires concerning their health, current medications, and PA level.

161 Although the participants studied here were asymptomatic for cardiovascular disease and 162 otherwise physically and cognitively healthy, many reported taking prescribed medications to 163 manage their cardiovascular health. We believe that healthy older adults are more likely to 164 manage their health with medications so our choice to include these participants more accurately 165 represents most older adults. Similar to our population, a 2003 study, found that $53.2 \%$ of adults 166 over 65 yrs. old were taking medications to manage their cardiovascular health (Gurwitz et. al., 167 2003). Eligible individuals participated in a single 120-minute session during which 168 sociodemographic and anthropometric measures, distance walked in the 6MWT, maximal hand169 grip strength, cognitive performance, and heart rate pre-, during, and each minute for up to 5 170 minutes post-6MWT were measured.

\section{Outcome Measures}

172 Sociodemographic characteristics (age, sex, ethnicity, medication use, yrs. of education) were 173 ascertained through self-report.

174 Physical activity level was determined using the Physical Activity Scale for the Elderly (PASE) 175 which is a reliable and valid instrument for the assessment of physical activity in community 
176 dwelling older adults (Washburn, Smith, Jette, \& Janney, 1993).

177 Anthropometric measures included height, weight, and body mass index (BMI). Height was

178 measured to the nearest $0.1 \mathrm{~cm}$ using a stadiometer (Seca Slider for 213 Mobile Stadiometer).

179 Weight was measured by using a Health O Meter Professional scale (Model 500KL) and

180 recorded to the nearest $0.1 \mathrm{~kg}$. Body mass index (BMI) was calculated according to the formula:

181 body mass $(\mathrm{kg})$ divided by height squared $\left(\mathrm{m}^{2}\right)$.

182 Cognitive Measures

183 Cognitive performance was assessed in 4 cognitive tests: the 3MS, Animal Naming, and TMT A

$184 \&$ B. To mitigate a learning effect, all participants were naïve to the cognitive tests.

185 The 3MS is a brief, general cognitive test battery assessing orientation, concentration, language,

186 and immediate and delayed memory (Teng \& Chui, 1987). Possible scores range from 0 to 102,

187 with higher scores indicating better cognitive performance. Two questions, the first related to the

188 suburb in which they were born and the second to the suburb in which they are located during the

189 3MS examination, were omitted; the maximum score was 100 points. The Animal Naming test

190 assesses verbal fluency (Rosen, 1980) and participants were instructed to "name as many animals

191 as they could think of." Performance was assessed as the total number of animal names

192 generated in one, continuous minute.

193 The TMT is a measure of visual scanning, complex attention, psychomotor speed, and mental

194 flexibility. The TMT consists of two parts A and B, each part consisting of 25 circles distributed

195 across an 8.5 by 11 -inch sheet of paper. In part A, circles are randomly arranged and numbered 1

196 through 25 on the page. Participants were instructed to draw a continuous line, without lifting

197 their pencil from the paper, to connect circles in numerical sequence from 1 to 25 . In part B,

198 participants were instructed to connect alternating letters and numbers in circles arranged

199 randomly on a page (i.e. 1-A-2-B). Tests were timed, and scores corresponded to the time to

200 completion.

201 Cognitive tests were administered and scored by third and fourth year kinesiology undergraduate

202 students who were trained on all cognitive tests by video and in-house workshops. Although no

203 inter-tester reliability assessments were performed, the authors regularly reviewed all

204 standardized procedures with testers and supervised data collection to ensure consistency across

205 all tests and examiners. In addition, Bassuk \& Murphy (2003) reported that interrater reliability

206 for the 3MS was high $(\mathrm{ICC}=0.98)$, and there was no evidence of rater bias, when trained 
207 laypeople administered the 3MS in community populations.

208 Physical Performance Measures

209 All 6MWT trials were conducted indoors according to standardized protocol (Lipkin, Scriven,

210 Crake, \& Poole-Wilson, 1986). Prior to the 6MWT, participants were familiarized and instructed

211 on the use of the Borg Rating of Perceived Exertion (RPE) scale. Before, and each minute during

212 the 6-min walk, participants were shown the RPE scale and asked to "indicate their level of

213 physical exertion" on a scale of " 1 - no exertion at all" to "10- maximal exertion."

214 Each participant was fitted with a chest strap to monitor heart rate (Polar FS2C, Polar Electro,

215 Oy, Kempele, Finland). Heart rate was recorded at rest after sitting quietly for 5 minutes, at each

216 minute during the 6MWT, and each minute for 5-minutes post-exercise. The highest heart rate

217 recorded during the $6 \mathrm{MWT}$ is $6 \mathrm{MWT} \mathrm{HR}_{\text {PEAK. }}$ All participants performed one $6 \mathrm{MWT}$ trial.

218 Participants were instructed to "cover as much distance as possible without jogging" during the

219 test. During the test, participants were encouraged by having testers say, "you're doing great" and

220 "keep up the good work." Each lapsed minute was called out to help with pacing.

221 Maximal hand-grip strength was assessed using a hand-grip dynamometer, recorded at $500 \mathrm{~Hz}$

222 using a Tel-100 system (Biopac Systems, Inc.) and laptop microcomputer. Specifically,

223 participants were tested while they were standing, shoulder adducted and neutrally rotated, elbow

224 extended, while the forearm and wrist joint were held in the neutral position, with arms against

225 their sides (Balogun, Akomolafe, \& Amusa, 1991). Three trials were performed for each hand

226 with a 1 min. rest between each trial. The peak value for each hand was subsequently determined

227 via Acqknowledge version 3.5.6 software (Biopac Systems, Inc.). The maximum value using

228 either hand was used for analyses.

229 Statistical Analysis

230 Descriptive statistics and bivariate analyses were conducted using Statistical Package for Social

231 Sciences (SPSS Inc., Chicago, IL, version 10.0). Values of $\mathrm{p}<0.05$ were considered to be

232 statistically significant. Data normality was determined with Kolmogorov-Smirnov tests before

233 analyses. Descriptive statistics presented as mean \pm standard deviation (SD) for normally

234 distributed data, median with interquartile range (IQR) for skewed data (non-Gaussian), and

235 frequencies with percentage for categorical data. Data were skewed for age, height, BMI, 6MWT

$236 \mathrm{HR}_{\mathrm{PEAK}}$, distance walked in the 6MWT, 3MS, TMT A and B, and peak hand-grip. Significant

237 differences between male and female participants were assessed with independent Student's t- 
238 test for normally distributed data, while the Mann-Whitney test was used for skewed data. PASE 239 was assessed as a continuous measure. Education levels were categorized with respect to whether 240 the participant had more than 16 years of education (college-educated and above). Ethnicity was 241 categorized as 1 = white, $2=$ Asian, $3=$ African American, $4=$ other, age was measured in years,

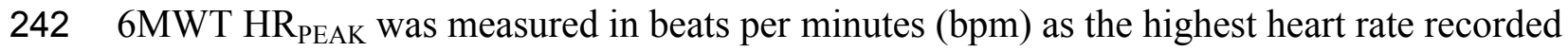
243 during the $6 \mathrm{MWT}$, and $\% \mathrm{HR}_{\max }$ was determined for each participant by calculating $\mathrm{HR}_{\max }=(220$ 244 - age), then $\left(\left(\mathrm{HR}_{\mathrm{PEAK}} / \mathrm{HR}_{\mathrm{MAX}}\right) * 100\right)=\% \mathrm{HR}_{\mathrm{MAX}}$. One participant was omitted from the $3 \mathrm{MS}$ 245 analysis $(\mathrm{n}=89)$ when a cutpoint score of 79 was applied to the 3MS scores (Teng et al., 1990). 246 Regression diagnostics were performed to determine whether assumptions underlying the linear 247 models were valid (linearity, equal variance, and normality of residuals), and analyses were 248 repeated after removal of specific points with high residual values or high levels of influence. 249 Thus, TMT A and B $(n=88)$ scores omitted for one participant, and TMT A $(n=87)$ omitted for 250 an additional participant. Data from the 3MS was rank transformed, and the TMTs A and B were $251 \log$ transformed before statistical modeling to avoid violating the assumption of normality.

252 Pearson product moment correlations (normally distributed data) and Spearman's rho 253 correlations (skewed data) were first used to assess the relationships between cognitive

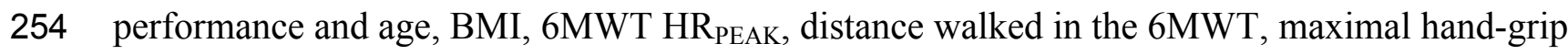
255 strength, and PASE. Variables found to significantly correlate with cognitive test performance in 256 the bivariate analyses were entered into forward multiple regression analyses with each cognitive 257 test as a dependent variable. $\beta$-blocker use was specifically identified from medication use 258 because it has been found to distort stress related heart rate response with the potential to affect 259 test scores when administered to high school students (Faigel, 1991). Ethnicity, sex, education 260 level and $\beta$-blocker use were suspected to contribute to cognitive performance; thus their effect 261 was examined under a multivariate regression model setting where a class statement was used to 262 recode the categorical variables into a set of separate binary variables, and a contrast matrix was 263 constructed to assess the effect among different levels of a categorical variable. Male and female 264 data were pooled for analyses. Model building and validation were initially compiled using 265 Statistical Analysis System software (SAS, version 9.4) and then validated using Statistical 266 Package for Social Sciences (SPSS Inc., Chicago, IL, version 10.0) at a .05 $\alpha$ level.

\section{Results}

268 Ninety-five participants ages 60-95 yrs. were recruited; however, 5 participants were excluded 
269 due to not meeting the inclusion criteria $(n=1)$, or missing test data $(n=4)$. Ninety participants 270 (69 females) with a mean age of $75 \pm 9.5$ yrs. participated in this study. Nearly 58 percent of our 271 population $(\mathrm{n}=52)$ self-identified as white, 12 participants identified as African American, 18 272 identified as Asian, and 8 self-reported to be from other ethnic backgrounds. Demographic, 273 clinical, and physical performance measures are presented in Table 1. Although males reported 274 completing significantly more years of education $(16.7 \pm 3.9$ vs. $14.5 \pm 2.8 \mathrm{yrs}$; $\mathrm{p}<0.05)$ and 275 generated significantly greater hand-grip strength $(19.7 \pm 7.9$ vs. $11.9 \pm 3.7 \mathrm{~kg} ; \mathrm{p}<0.001)$ males 276 vs. females, respectively), no other significant differences were found between males and 277 females in our population. Thus, male and female data were pooled for analyses. The cognitive 278 performance measures for all participants are shown in Table 2.

279 Sociodemographic, physiologic, physical performance correlates of 3MS

280 According to the bivariate analyses, neither BMI $(r=-0.045, p=0.676)$ nor PASE $(r=0.197, p$ $281=0.065)$ were associated with ranked $3 \mathrm{MS}$ performance. However, age $(\mathrm{r}=-0.349, \mathrm{p}<0.001)$ 282 moderately and negatively correlated with ranked 3MS performance. Distance walked in the 283 6MWT $(\mathrm{r}=0.384, \mathrm{p}<0.001), 6 \mathrm{MWT} \mathrm{HR}_{\text {PEAK }}(\mathrm{r}=0.300, \mathrm{p}<0.004)$, and peak hand-grip

284 285 286 287 288 289 290 291

292 293 294 295 296

297 298 299 strength $(\mathrm{r}=0.297, \mathrm{p}=0.006)$ were moderate and positively correlated with ranked $3 \mathrm{MS}$ performance, and thus were entered into the final model. Table 3 shows the final model which explained $33.3 \%$ of the total variance in $3 \mathrm{MS}$ scores $\left(\mathrm{R}^{2}=0.333, \mathrm{~F}(3,85)=15.677, \mathrm{p}<0.001\right)$. After adjusting for sociodemographics (age, ethnicity, education) and $\beta$-blocker use, higher

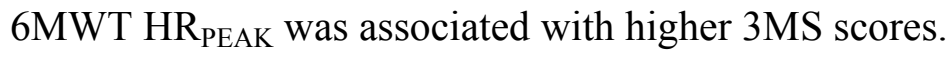

Sociodemographic, physiologic, physical performance correlates of Animal Naming

Correlations revealed that neither BMI $(r=0.125, \mathrm{p}=0.242)$ nor peak hand-grip $(\mathrm{r}=0.125, \mathrm{p}=$ $0.253)$ correlated with Animal Naming performance, but age $(\mathrm{r}=-0.355, \mathrm{p}<0.001)$ was moderately and negatively correlated with Animal Naming test performance. Distance walked in

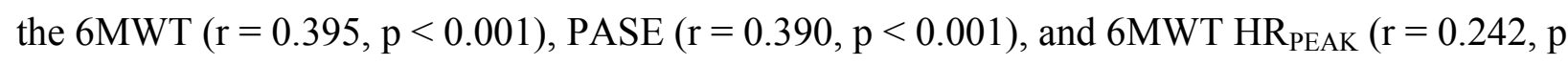
$=0.022$ ) were moderately and positively correlated with Animal Naming test performance and thus, were entered into the final model. Table 4 shows the final model which explained $32.1 \%$ of the total variance $\left(\mathrm{R}^{2}=0.321,(\mathrm{~F}(4,85)=11.496, \mathrm{p}<0.001)\right.$. After adjusting for sociodemographics (age, ethnicity, education) and $\beta$-blocker use, PASE independently and positively correlated with Animal Naming performance ( $p$-value $=0.001$ ). Higher levels of selfreported PA on the PASE were associated with better performance on the Animal Naming test. 
300 In contrast, $\beta$-blocker use was found to negatively correlate with Animal Naming performance 301 (p-value $=0.035)$. On average, self-reported $\beta$-blocker users scored 2.1 points lower on the 302 Animal Naming test, compared with non-users.

303 Sociodemographic, physiologic, physical performance correlates of TMT A

304 Correlations revealed that neither BMI $(\mathrm{r}=0.070, \mathrm{p}=0.522)$ nor peak hand-grip $(\mathrm{r}=-0.001, \mathrm{p}=$ 305 0.996) correlated with log-transformed Trailmaking A performance. However, age $(r=0.411, p$ $306<0.001)$ was positively, while education level $(\mathrm{r}=-0.356, \mathrm{p}=0.001)$, PASE $(\mathrm{r}=-0.341, \mathrm{p}=$

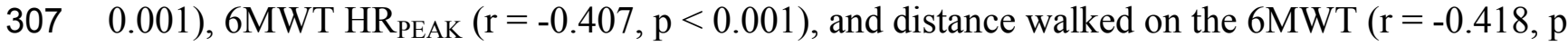
$308<0.001)$ were moderately and negatively correlated with TMT A time to completion. Table 5 309 shows the final model which explained $25.2 \%$ of the total variance $\left(\mathrm{R}^{2}=0.252,(\mathrm{~F}(3,83)=\right.$ 310 10.644, $\mathrm{p}<0.001$ ). Controlling for sociodemographics (age, ethnicity, education), both PASE

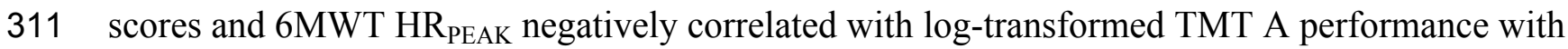
312 p-values $=0.017$ and $<0.001$, respectively. This means that higher $6 \mathrm{MWT} \mathrm{HR} \mathrm{PEAK}_{\mathrm{P}}$ and PASE 313 scores were associated with a faster TMT A time to completion, or better test performance.

314 Sociodemographic, physiologic, physical performance correlates of TMT B

315 Correlations revealed that neither BMI $(r=0.070, p=0.522)$, PASE $(r=-0.142, p=0.186)$, nor 316 peak hand-grip $(\mathrm{r}=-0.017, \mathrm{p}=0.877)$ correlated with log-transformed Trailmaking B 317 performance. However, age $(\mathrm{r}=0.387, \mathrm{p}<0.001)$ was moderately and positively associated with 318 TMT B time to completion while education level $(\mathrm{r}=-0.406, \mathrm{p}<0.001), 6 \mathrm{MWT} \mathrm{HR}_{\text {PEAK }}(\mathrm{r}=$ $3190.411, \mathrm{p}<0.001)$, and 6MWT distance $(\mathrm{r}=-0.328, \mathrm{p}=0.002)$ were moderately and negatively 320 associated with TMT B time to completion. Thus, these variables were entered into the final 321 model (Table 6$)$ and accounted for $25.1 \%$ of the total variance $\left(\mathrm{R}^{2}=0.251,(\mathrm{~F}(3,84)=10.739, \mathrm{p}\right.$ $322<0.001$ ). Controlling for sociodemographics (age, ethnicity, education level), 6MWT HR $\mathrm{PEAK}_{\mathrm{P}}$ 323 was negatively correlated with TMT B time to completion with a p-value $<0.05$. This means that 324 higher 6MWT HR PEAK was associated with a faster TMT B time to completion, or better test 325 performance. 


\section{Discussion}

328 Main findings of the current study were: 1$)$ exercise intensity $\left(6 \mathrm{MWT} \mathrm{HR} \mathrm{HEAK}_{\mathrm{PE}}\right)$ recorded during 329 the 6MWT was correlated with better performance on a range of cognitive tests (3MS and TMT 330 A \& B); this correlation remained after adjusting for sociodemographics, 2) higher PA levels 331 reported on the PASE was correlated with better performance on verbal fluency (Animal

332 Naming) and TMT A, 3) distance walked in the 6MWT was associated with better performance 333 on cognitive tests; however these relationships were no longer evident after controlling for 334 sociodemographics (age, ethnicity, education), 4) no relationship was found between maximal 335 hand-grip strength and performance on cognitive tests, and 5) a negative correlation was found 336 with $\beta$-blocker use and verbal fluency (Animal Naming).

337 In the current study, higher $\mathrm{HR}_{\text {PEAK }}$ during the 6MWT was positively correlated with cognitive

338 performance in the $3 \mathrm{MS}$ and TMT A and B. These findings are in agreement with evidence that 339 has shown intensity of PA positively influences cognitive abilities (Van Gelder, et al., 2004;

340 Angevaren et al., 2007; Brown et al., 2012). Longitudinal studies found that higher self-reported

341 PA intensity preserved cognitive function in middle aged and older adults tested over a four

342 (Angevaren et al., 2007) and ten-year follow-up period (Van Gelder et al., 2004). In a cross-

343 sectional study, direct measures of daily PA intensity were assessed with an Actigraph monitor

344 and those in the higher intensity tertiles scored higher on cognitive tests (Brown et al., 2012).

345 Our study findings are unique in that peak heart rate recorded during the 6MWT provided a 346 direct and easily obtained measure of exercise intensity that was correlated with cognitive 347 performance measures.

348 In the bivariate correlations performed here, distance walked in the 6MWT was correlated with 349 cognitive performance (3MS, Animal Naming, and TMT A \& B), but after adjusting for 350 confounding variables such as age, distance walked was no longer associated with global 351 cognitive functioning. These results are consistent with those of Lord \& Menz (2002) in which 352 the association between cognitive and physical performance disappeared after controlling for 353 age. Matthé et al., (2015) included participants using walking aids, and found that those 354 participants who did not use walking aids, covered more distance in the 6MWT and scored 355 higher on the MMSE. However, sample size was much smaller $(n=27)$ and confounding 356 variables such as age were not controlled. In addition, our population may have been more 357 physically homogeneous than populations in previous studies, thus associations with PA may 
358 have been more difficult to resolve in this study.

359 Physical activity as self-reported in the PASE maintained a positive association with Animal

360 Naming performance after controlling for age, ethnicity, and education level. This association

361 might be partially explained by the positive influence of PA on psychomotor function in older

362 adults (Rodríguez-Aranda, Waterloo, Sparr, \& Sundet, 2006; Rosano et al., 2010). Evidence of

363 an age-associated slowing of psychomotor function has been demonstrated as the slowing of

364 handwriting, reading speed and time required to say a particular word in older participants

365 (Eggermont et al., 2009). Additionally, PA may be associated with the frequency of social

366 interactions (e.g. group exercise, exercise with a friend) and a higher PASE score may reflect

367 less social isolation. This is in part supported by McAuley, Jerome, Elavsky, Marquez, \&

368 Ramsey, (2003) who found self-reported PA levels assessed by PASE to be influenced by

369 perceptions of social support with higher perceived support associated with increased self-

370 efficacy and improved exercise adherence.

371 Maximal hand-grip strength was not found to be associated with cognitive performance, a

372 finding that remains equivocal in the literature. Systematic reviews support the use of hand-grip

373 measures to predict numerous outcomes, including mortality, functional limitations, activity

374 levels, and independence, these measures most likely reflecting multidimensional variables that

375 contribute to future risk in older adults (Bohannon, 2001; Bohannon, 2008). Cross-sectional and

376 longitudinal studies suggest that muscular strength measures are positively associated with

377 cognitive performance (Enright et. al., 2003; Lord \& Menz, 2002; Alfaro-Acha et al., 2006;

378 Taekema et al., 2010; Ling et al., 2010). Longitudinal studies point to hand-grip as a significant

379 predictor of cognitive decline in 555 participants, 85 years of age, followed for 4 years (Taekema

380 et al., 2010) and in 2,160 older Mexican Americans 65 years and older followed for a 7-year

381 period (Alfaro-Acha, et al., 2006), however this association was no longer significant after

382 controlling for age (Lord \& Menz, 2002). Also, some participants in our study complained of

383 limited ability to perform the hand-grip strength test due to arthritic conditions, which may have

384 limited our ability to detect an association between grip strength and cognitive performance.

385 Perhaps with a larger sample and/or a longitudinal study, a temporal association would emerge.

386 The negative correlation between $\beta$-blocker use and verbal fluency is an interesting one and

387 warrants further investigation. Similar to results from Qato et al. (2008), 83\% (75 of 90

388 participants) reported regular use of medications to manage chronic health conditions, and $\sim 21 \%$ 
389 of these participants (16 of 75 participants) reported using $\beta$ - blockers. Beta blockade has been

390 found to abolish the stress induced rise in heart rate (Benschop et al., 1994) and when

391 administered to students with paralyzing test anxiety, improved Scholastic Aptitude Test scores

392 (Faigel, 1991). Further benefit has been attributed to tests of cognitive flexibility (Alexander,

393 Hillier, Smith, Tivarus, \& Beversdorf, 2007), but the authors are not aware of research links to

394 verbal fluency.

395 Although the current study was not designed to test a specific mechanism, possible explanations

396 exist and justify further research. Regular exercise at higher intensities improves cardiovascular

397 health, cardiorespiratory fitness, lipid profiles, and is believed to benefit cerebral blood flow

398 (Van Gelder et al., 2004; Kraus et. al., 2002; Rogers, Meyer, \& Mortel, 1990), a theory in part

399 supported by a cross-sectional study showing that cerebral blood flow reductions in sedentary

400 older adults are associated with impaired cognitive performance (Rogers et al., 1990). Additional

401 mechanisms include the exercise-stimulated rise in growth factors believed to promote

402 hippocampal synaptic plasticity and neurogenesis (Cotman, Berchtold, \& Christie, 2007; Gómez-

403 Pinilla, So, \& Kesslak, 1998; Van Praag, Christie, Sejnowski, \& Gage, 1999).

404 In our study, a higher peak exercise intensity during the 6MWT was associated with better

405 cognitive performance. The 6MWT is a test of functional capacity, and as such depends on the

406 health and functioning of multiple systems (Stewart, Melton-Rogers, Morrison, \& Figoni, 2000)

407 including the cardiovascular and muscular systems. Our results show that a higher exercise

408 intensity during an acute exercise test (i.e. the 6MWT) is correlated with better cognitive

409 performance. We assume that higher heart rate during the 6MWT is indicative of chronic

410 physical training effects on the heart. However, additional studies are needed to test whether

411 chronically training at higher intensities benefits cognitive performance in older adults.

412 In this population of ethnically diverse older adults, ethnicity correlated with performance in the

413 3MS and Animal Naming even after controlling for self-reported education level. Work by

414 Manly, Touradji, Tang, \& Stern (2003) suggests that in multi-ethnic older adults, cognitive test

415 performance should be interpreted relative to education quality, not years of formal education. In

416 a population of ethnically diverse community dwelling older adults, Manly, Jacobs, Touradji,

417 Small, \& Stern (2002) found that African American older adults obtained significantly lower

418 scores than whites on measures of word list learning and memory, figure memory, abstract

419 reasoning, fluency, and visuospatial skill even though the groups were matched on years of 
420 education. However, after adjusting for education quality, the overall effect of ethnicity was 421 greatly reduced and ethnicity differences on tests became nonsignificant. Culture, ethnicity, and 422 poverty affect education quality so that years of education and quality of education are not 423 comparable in a population of multi-ethnic older adults (Weiss \& Stern, 2013).

424 It is worth noting that despite reaching significance, the standardized coefficients ( $\beta$-weights) 425 indicated a moderate ability to predict cognition, a finding that is consistent with other cross426 sectional (Sprague, Watts, \& Burns, 2016; Hultsch, Hammer \& Small, 1993; Baldasseroni et al., 427 2010; Angevaren et al., 2007) and longitudinal studies (Aichberger et al., 2010). Distance walked 428 during the 6MWT was found to be a significant predictor of MMSE in patients with chronic 429 heart failure $(\beta=0.20)$ (Baldasseroni et al., 2010), and selected PASE items predicted cognition 430 ( $\beta$-weights ranging from 0.30-0.31) (Sprague, Watts, \& Burns, 2016) as well as self-reported 431 measures of activity frequency ( $\beta$-weight of 0.019-0.262 (Hultsch, Hammer \& Small, 1993). 432 Angevaren et al. (2007) and Aichberger et al. (2010) found intensity to be predictive of cognition 433 with $\beta$-weights that ranged from $0.16-0.46$. These findings are consistent with ours and suggest 434 that the relationship between physical activity or exercise intensity, and cognitive performance is 435 complex and not fully understood, with ethnicity in the current study modifying this relationship. 436 In conclusion, although the 6MWT is a practical measure, there are inherent limits as to what can 437 be assessed and additional studies are needed to elucidate other contributors.

438 Study limitations include the cross-sectional study design and homogeneity of our population. It 439 is possible that physical exercise is a marker for a healthy lifestyle; better overall health linked to 440 cognitive health, however our data are unable to ascribe direction of causality. Additionally, 441 many of our participants were recruited from local fall prevention/fitness programs and thus 442 likely to represent a segment of more active persons aged 60 to 95 years. Other limitations 443 include that we did not test for educational quality in our sample of multi-ethnic older adults, and 444 facility and participant scheduling constraints precluded us from offering an acclimation period 445 for the 6MWT. Finally, while our findings show that a higher intensity $\left(\mathrm{HR}_{\mathrm{PEAK}}\right)$ during the 446 6MWT was associated with better performance on a range of cognitive tests, we did not control 447 the intensity at which participants walked but allowed them to self-pace during the 6MWT.

\section{Conclusion}

449 Present study found a lack of association between grip strength and distance walked, and 450 cognition, and $\beta$-blocker use negatively correlated to verbal fluency. Authors speculate that 
451 arthritis in participants' hands limited grip strength, and our homogeneous sample prevented 452 distance walked from being isolated as a contributor to cognitive performance. Additionally, 453 authors are not aware of previous research linking $\beta$-blocker use to verbal fluency, although 454 Faigel (1991) reports a reduction in test anxiety and improved Scholastic Aptitude Scores. These 455 findings warrant future testing that controls for these variables. Self-reported PASE measures 456 were associated with Animal Naming perhaps reflecting reduced social isolation and slowing of 457 psychomotor function associated with physical activity.

458 Key to this study, was to identify safe, inexpensive and field-amenable methods to monitor 459 cognition in community dwelling older adults. A submaximal field test, such as the 6MWT, may 460 be part of that solution. Peak exercise intensity during the 6MWT is a simple and reliable 461 measure of functional capacity, and is related to cognitive performance in multi-ethnic, 462 community dwelling older adults (ages 60-95 yrs.). This is promising because it suggests that a 463 submaximal field test may be used to monitor age-related changes in executive function and 464 higher order processing. Thus, physicians, exercise professionals, and/or fitness/fall prevention 465 programs could use this short, physical test to monitor cognition and motivate people to remain 466 active with age.

467 Acknowledgements

468 Thank you to: Elizabeth Johnson, Brendan Jordan, Kevin Medina, Joaquin Tabera, Nang Ei Ei 469 Mon, Ritika Vashisht, Cindayanne Camarse, Sherri Morioka, Roger Chandler, and Christopher 470 Bayesdorfer, PhD. 


\section{References}

473 Abbott, R. D., White, L. R., Ross, G. W., Masaki, K. H., Curb, J. D., \& Petrovitch, H. (2004).

474 Walking and dementia in physically capable elderly men. JAMA, 292(12), 1447-1453.

475 Aichberger, M. C., Busch, M. A., Reischies, F. M., Ströhle, A., Heinz, A., \& Rapp, M. A.

476 (2010). Effect of physical inactivity on cognitive performance after 2.5 years of follow-up.

477 GeroPsych.

478 Alexander, J. K., Hillier, A., Smith, R. M., Tivarus, M. E., \& Beversdorf, D. Q. (2007). Beta-

479 adrenergic modulation of cognitive flexibility during stress. Journal of cognitive

480 neuroscience, 19(3), 468-478.

481 Alfaro-Acha, A., Snih, S. A., Raji, M. A., Kuo, Y. F., Markides, K. S., \& Ottenbacher, K.J.

482 (2006). Handgrip strength and cognitive decline in older Mexican Americans. The Journals of

483 Gerontology Series A: Biological Sciences and Medical Sciences, 61(8), 859-865.

484 Angevaren, M., Vanhees, L., Wendel-Vos, W., Verhaar, H. J., Aufdemkampe, G., Aleman, A., \&

485 Verschuren, W. M. (2007). Intensity, but not duration, of physical activities is related to

486 cognitive function. European Journal of Cardiovascular

487 Prevention \& Rehabilitation, 14(6), 825-830.

488 Baldasseroni, S., Mossello, E., Romboli, B., Orso, F., Colombi, C., Fumagalli, S., ... \&

489 Marchionni, N. (2010). Relationship between cognitive function and 6-minute walking test in

490 older outpatients with chronic heart failure. Aging clinical and experimental research, 22(4),

$491308-313$.

492 Balogun, J. A., Akomolafe, C. T., \& Amusa, L. O. (1991). Grip strength: effects of testing

493 posture and elbow position. Archives of physical medicine and rehabilitation, 72(5), 280-283.

494 Barnes, D. E., Yaffe, K., Satariano, W. A., \& Tager, I. B. (2003). A longitudinal study of

495 cardiorespiratory fitness and cognitive function in healthy older adults. Journal of the American

496 Geriatrics Society, 51(4), 459-465.

497 Bassuk, S. S., \& Murphy, J. M. (2003). Characteristics of the modified mini-mental state exam

498 among elderly persons. Journal of Clinical Epidemiology, 56(7), 622-628.

499 https://doi.org/10.1016/S0895-4356(03)00111-2. 
500 Benschop, R. J., Nieuwenhuis, E. E., Tromp, E. A., Godaert, G. L., Ballieux, R. E., \& van

501 Doornen, L. J. (1994). Effects of beta-adrenergic blockade on immunologic and cardiovascular

502 changes induced by mental stress. Circulation, 89(2), 762-769.

503 Bherer, L., Erickson, K. I., \& Liu-Ambrose, T. (2013). A review of the effects of physical

504 activity and exercise on cognitive and brain functions in older adults. Journal of aging research, 5052013.

506 Bohannon, R. W. (2001). Dynamometer measurements of hand-grip strength predict multiple

507 outcomes. Perceptual and motor skills, 93(2), 323-328.

508 Bohannon, R. W. (2008). Hand-grip dynamometry predicts future outcomes in aging adults.

509 Journal of geriatric physical therapy, 31(1), 3-10.

510 Boyle, P. A., Buchman, A. S., Wilson, R. S., Leurgans, S. E., \& Bennett, D. A. (2009).

511 Association of muscle strength with the risk of Alzheimer disease and the rate of cognitive

512 decline in community-dwelling older persons. Archives of neurology, 66(11), 1339-1344.

513 Brown, B. M., Peiffer, J. J., Sohrabi, H. R., Mondal, A., Gupta, V. B., Rainey-Smith, S.R., ... \&

514 Masters, C. L. (2012). Intense physical activity is associated with cognitive performance in the

515 elderly. Translational psychiatry, 2(11), e191.

516 Chodzko-Zajko, W. J., Proctor, D. N., Singh, M. A. F., Minson, C. T., Nigg, C. R., Salem, G. J.,

517 \& Skinner, J. S. (2009). Exercise and physical activity for older adults. Medicine \& science in 518 sports \& exercise, 41(7), 1510-1530.

519 Cotman, C. W., Berchtold, N. C., \& Christie, L. A. (2007). Exercise builds brain health: key

520 roles of growth factor cascades and inflammation. Trends in neurosciences, 30(9), 464-472.

521 Cress, M. E., Buchner, D. M., Prohaska, T., Rimmer, J., Brown, M., Macera, C., ... \& Chodzko-

522 Zajko, W. (2005). Best practices for physical activity programs and behavior counseling in older 523 adult populations. Journal of aging and physical activity, 13(1), 61-74.

524 Desmond, D. W., Tatemichi, T. K., Paik, M., \& Stern, Y. (1993). Risk factors for

525 cerebrovascular disease as correlates of cognitive function in a stroke-free cohort. Archives of 526 Neurology, 50(2), 162-166.

527 Dunbar, C. C., \& Kalinski, M. I. (2004). Using RPE to regulate exercise intensity during a 20-

528 week training program for postmenopausal women: a pilot study. Perceptual and motor skills, 
529

530 Eggermont, L. H., Milberg, W. P., Lipsitz, L. A., Scherder, E. J., \& Leveille, S. G. (2009).

531 Physical activity and executive function in aging: the MOBILIZE Boston Study. Journal of the

532 American Geriatrics Society, 57(10), 1750-1756.

533 Enright, P. L., McBurnie, M. A., Bittner, V., Tracy, R. P., McNamara, R., Arnold, A., \&

534 Newman, A. B. (2003). The 6-min walk test: a quick measure of functional status in elderly 535 adults. CHEST Journal, 123(2), 387-398.

536 Faigel, H. C. (1991). The effect of beta blockade on stress-induced cognitive dysfunction in 537 adolescents. Clinical pediatrics, 30(7), 441-445.

538 Farina, E., Magni, E., Ambrosini, F., Manfredini, R., Binda, A., Sina, C., \& Mariani, C. (1997).

539 Neuropsychological deficits in asymptomatic atrial fibrillation. Acta neurologica scandinavica, 540 96(5), 310-316.

541 Gómez-Pinilla, F., So, V., \& Kesslak, J. P. (1998). Spatial learning and physical activity

542 contribute to the induction of fibroblast growth factor: neural substrates for increased cognition 543 associated with exercise. Neuroscience, 85(1), 53-61.

544 Grange, C. C., Maire, J., Groslambert, A., Tordi, N., Dugue, B., Pernin, J. N., \& Rouillon, J. D.

545 (2004). Perceived exertion and rehabilitation with arm crank in elderly patients after total hip 546 arthroplasty: A preliminary study. Journal of Rehabilitation Research \& Development, 41(4).

547 Gurwitz, J. H., Field, T. S., Harrold, L. R., Rothschild, J., Debellis, K., Seger, A. C., ... \& Bates, 548 D. W. (2003). Incidence and preventability of adverse drug events among older persons in the 549 ambulatory setting. JAMA, 289(9), 1107-1116.

550 Hall, K. S., Howe, C. A., Rana, S. R., Martin, C. L., \& Morey, M. C. (2013). METs and 551 accelerometry of walking in older adults: standard versus measured energy cost. Medicine and 552 science in sports and exercise, 45(3), 574.

553 Hogan, C. L., Mata, J., \& Carstensen, L. L. (2013). Exercise holds immediate benefits for affect 554 and cognition in younger and older adults. Psychology and aging, 28(2), 587.

555 Hultsch, D. F., Hammer, M., \& Small, B. J. (1993). Age differences in cognitive performance in 556 later life: Relationships to self-reported health and activity lifestyle. Journal of Gerontology, 557 48(1), P1-P11. 
558 Kirk-Sanchez, N. J., \& McGough, E. L. (2014). Physical exercise and cognitive performance in 559 the elderly: current perspectives. Clinical interventions in aging, 9, 51.

560 Kraus, W. E., Houmard, J. A., Duscha, B. D., Knetzger, K. J., Wharton, M. B., McCartney, J. S., 561 ... \& Kulkarni, K. R. (2002). Effects of the amount and intensity of exercise on plasma 562 lipoproteins. New England Journal of Medicine, 347(19), 1483-1492.

563 Laurin, D., Verreault, R., Lindsay, J., MacPherson, K., \& Rockwood, K. (2001). Physical 564 activity and risk of cognitive impairment and dementia in elderly persons. Archives of neurology, 565 58(3), 498-504.

566 Ling, C. H., Taekema, D., De Craen, A. J., Gussekloo, J., Westendorp, R. G., \& Maier, A. B. 567 (2010). Handgrip strength and mortality in the oldest old population: the Leiden 85-plus study.

568 Canadian Medical Association Journal, 182(5), 429-435.

569 Lipkin, D. P., Scriven, A. J., Crake, T., \& Poole-Wilson, P. A. (1986). Six minute walking test 570 for assessing exercise capacity in chronic heart failure. Br Med J (Clin Res Ed), 292(6521), 653571655.

572 Lord, S. R., \& Menz, H. B. (2002). Physiologic, psychologic, and health predictors of 6-minute 573 walk performance in older people. Archives of physical medicine and rehabilitation, 83(7), 907574911.

575 Manly, J. J., Jacobs, D. M., Touradji, P., Small, S. A., \& Stern, Y. (2002). Reading level 576 attenuates differences in neuropsychological test performance between African American and 577 White elders. Journal of the International Neuropsychological Society, 8(03), 341-348.

578 https://doi.org/10.1017/S1355617702813157

579 Manly, J. J., Touradji, P., Tang, M.-X., \& Stern, Y. (2003). Literacy and Memory Decline 580 Among Ethnically Diverse Elders. Journal of Clinical and Experimental Neuropsychology

581 (Neuropsychology, Development and Cognition: Section A), 25(5), 680-690.

582 https://doi.org/10.1076/jcen.25.5.680.14579

583 Matthé, A., Roberson, D. N., \& Netz, Y. (2015). The relationship between cognitive and physical 584 function among residents of a Czech senior home. Acta Gymnica, 45(4), 159-165.

585 McAuley, E., Jerome, G. J., Elavsky, S., Marquez, D. X., \& Ramsey, S. N. (2003). Predicting 586 long-term maintenance of physical activity in older adults. Preventive medicine, 37(2), 110-118. 
587 Moul, J.L., Goldman, B., \& Warren, B. (1995). Physical activity and cognitive performance in 588 the older population. Journal of Aging and Physical Activity, 3(2), 135-145.

589 Nelson, M. E., Rejeski, W. J., Blair, S. N., Duncan, P. W., Judge, J. O., King, A. C., ... \& 590 Castaneda-Sceppa, C. (2007). Physical activity and public health in older adults:

591 recommendation from the American College of Sports Medicine and the American Heart 592 Association. Circulation, 116(9), 1094.

593 Özkaya, G. Y., Aydin, H., Toraman, F. N., Kizilay, F., Özdemir, Ö., \& Cetinkaya, V. (2005).

594 Effect of strength and endurance training on cognition in older people. Journal of sports science $595 \&$ medicine, 4(3), 300.

596 Plassman, B. L., Langa, K. M., Fisher, G. G., Heeringa, S. G., Weir, D. R., Ofstedal, M. B., ... \& 597 Steffens, D. C. (2008). Prevalence of cognitive impairment without dementia in the United 598 States. Annals of internal medicine, 148(6), 427-434.

599 Qato, D. M., Alexander, G. C., Conti, R. M., Johnson, M., Schumm, P., \& Lindau, S. T. (2008).

600 Use of prescription and over-the-counter medications and dietary supplements among older 601 adults in the United States. JAMA, 300(24), 2867-2878.

602 Riebe, D., Franklin, B. A., Thompson, P. D., Garber, C. E., Whitfield, G. P., Magal, M., \& 603 Pescatello, L. S. (2015). Updating ACSM's recommendations for exercise preparticipation health 604 screening. Medicine \& Science in Sports \& Exercise, 47(11), 2473-2479.

605 Rikli, R. E., \& Jones, C. J. (1998). The reliability and validity of a 6-minute walk test as a 606 measure of physical endurance in older adults. Journal of aging and physical activity, 6(4), 363607375.

608 Roberts, H. C., Denison, H. J., Martin, H. J., Patel, H. P., Syddall, H., Cooper, C., \& Sayer, A. A. 609 (2011). A review of the measurement of grip strength in clinical and epidemiological studies:

610 towards a standardised approach. Age and Ageing, 40(4), 423-429.

611 https://doi.org/10.1093/ageing/afr051

612 Rodríguez-Aranda, C., Waterloo, K., Sparr, S., \& Sundet, K. (2006). Age-related psychomotor 613 slowing as an important component of verbal fluency. Journal of neurology, 253(11), 1414.

614 Rogers, R. L., Meyer, J. S., \& Mortel, K. F. (1990). After reaching retirement age physical 615 activity sustains cerebral perfusion and cognition. Journal of the American Geriatrics Society, 
$61638(2), 123-128$.

617 Rosano, C., Venkatraman, V. K., Guralnik, J., Newman, A. B., Glynn, N. W., Launer, L., ... \& 618 Aizenstein, H. (2010). Psychomotor speed and functional brain MRI 2 years after completing a 619 physical activity treatment. The Journals of Gerontology Series A: Biological Sciences and 620 Medical Sciences, 65A(6), 639-647.

621 Rosen, W. G. (1980). Verbal fluency in aging and dementia. Journal of Clinical and 622 Experimental Neuropsychology, 2(2), 135-146.

623 Sprague, B. N., Watts, A. S., \& Burns, J. M. (2016). Relationship Between Physical Activity and 624 Cognition in Adults With and Without Alzheimer's Disease. Psi Chi Journal of Psychological 625 Research, 21(2).

626 Stewart, M. W., Melton-Rogers, S. L., Morrison, S., \& Figoni, S. F. (2000). The measurement 627 properties of fitness measures and health status for persons with spinal cord injuries. Archives of 628 physical medicine and rehabilitation, 81(4), 394-400.

629 Taekema, D. G., Gussekloo, J., Maier, A. B., Westendorp, R. G., \& de Craen, A. J. (2010).

630 Handgrip strength as a predictor of functional, psychological and social health. A prospective 631 population-based study among the oldest old. Age and ageing, 39(3), 331-337.

632 Tarumi, T., Gonzales, M. M., Fallow, B., Nualnim, N., Pyron, M., Tanaka, H., \& Haley, A. P. 633 (2013). Central artery stiffness, neuropsychological function, and cerebral perfusion in sedentary 634 and endurance-trained middle-aged adults. Journal of hypertension, 31(12), 2400-2409.

635 Teng, E. L., \& Chui, H. C. (1987). The Modified Mini-Mental State (3MS) examination. The 636 Journal of clinical psychiatry, 48(8), 314.

637 Teng, E. L., Chui, H. C., \& Gong, A. (1990). Comparisons between the Mini-Mental 638 State Exam (MMSE) and its modified version: the 3MS test. Psychogeriatrics: biomedical and 639 social advances, 59, 189-192.

640 Van Gelder, B. M., Tijhuis, M. A. R., Kalmijn, S., Giampaoli, S., Nissinen, A., \& Kromhout, D. 641 (2004). Physical activity in relation to cognitive decline in elderly men The FINE Study.

642 Neurology, 63(12), 2316-2321.

643 Van Praag, H., Christie, B. R., Sejnowski, T. J., \& Gage, F. H. (1999). Running enhances 
644 neurogenesis, learning, and long-term potentiation in mice. Proceedings of the National

645 Academy of Sciences, 96(23), 13427-13431.

646 Warburton, D. E., Nicol, C. W., \& Bredin, S. S. (2006). Prescribing exercise as preventive 647 therapy. Canadian Medical Association Journal, 174(7), 961-974.

648 Washburn, R. A., Smith, K. W., Jette, A. M., \& Janney, C. A. (1993). The Physical Activity

649 Scale for the Elderly (PASE): development and evaluation. Journal of clinical epidemiology, 650 46(2), 153-162.

651 Weiss, C. C., \& Stern, Y. (2013). 13 Literacy and cognitive decline among ethnically diverse 652 elders. Cognitive Reserve: Theory and Applications, 219.

653 Ylikoski, R., Ylikoski, A., Raininko, R., Keskivaara, P., Sulkava, R., Tilvis, R., \& Erkinjuntti, T. 654 (2000). Cardiovascular diseases, health status, brain imaging findings and neuropsychological 655 functioning in neurologically healthy elderly individuals. Archives of gerontology and geriatrics, $65630(2), 115-130$. 


\section{Table $\mathbf{1}$ (on next page)}

Participant Demographic, Clinical, and Physical Performance Measures 
1

\begin{tabular}{|c|c|}
\hline Variables & $\mathbf{n}=\mathbf{9 0}$ \\
\hline Male (\%) & $21(23.33)$ \\
\hline Female $(\%)$ & $69(76.67)$ \\
\hline Continuous Variables & $\mathbf{n}=\mathbf{9 0}$ \\
\hline Age (years) & $74(67,81.8)$ \\
\hline Education (years) & $15.1 \pm 3.2$ \\
\hline BMI $\left(\mathrm{kg} / \mathrm{m}^{2}\right)$ & $25.5(22.8,28.8)$ \\
\hline 6MWT (m) & $463.4(387.3,543.8)$ \\
\hline 6MWT HR PEAK (bpm) & $112.5(100.5,132.3)$ \\
\hline 6MWT \%HR MAX & $74.7 \pm 11.9$ \\
\hline RPE $_{\text {PEAK }}$ & $4.7 \pm 2.1$ \\
\hline Peak hand grip (kg) & $13.4(10,15.8)$ \\
\hline PASE & $162.1 \pm 78.8$ \\
\hline \multicolumn{2}{|c|}{$\begin{array}{l}\text { Abbreviations: BMI, body mass index; } 6 \mathrm{MWT}, 6 \text { Minute Walk Test; } 6 \mathrm{MWT} \mathrm{HR}_{\mathrm{PEAK}} \text {, Peak } \\
\text { heart rate recorded during the } 6 \mathrm{MWT} \text {; } 6 \mathrm{MWT} \% \mathrm{HR}_{\mathrm{MAX}} \text {, Peak heart rate during the } 6 \mathrm{MWT} \text { as } \\
\text { a percentage of age-predicted maximal heart rate; } \mathrm{RPE}_{\mathrm{PEAK}} \text {, Peak Relative Perceived Exertion } \\
\text { during the 6MWT; PASE, Physical activity scale of the elderly }\end{array}$} \\
\hline \multicolumn{2}{|c|}{$\begin{array}{l}\text { Notes: Data are presented as mean } \pm \text { SD for normally distributed data, median }(Q 75, Q 25) \text { for } \\
\text { skewed data, or } \mathrm{n} \text { (percentage) for categorical data }\end{array}$} \\
\hline
\end{tabular}


Table 2 (on next page)

Cognitive Test Performance 
1

\begin{tabular}{|l|l|l|l|}
\hline Continuous Variables & n & Range & Mean/Median \\
\hline 3MS (score) & 89 & $81-100$ & $96(93.1,95.4)$ \\
\hline Animal Naming (score) & 90 & $7-22$ & $18 \pm 4$ \\
\hline TMT A (seconds) & 87 & $15-162$ & $33(26.8,43.8)$ \\
\hline TMT B (seconds) & 88 & $35-280$ & $80(79,127.3)$ \\
\hline
\end{tabular}

Abbreviations: 3MS, Modified Mini-Mental State Test; TMT, Trailmaking Test

Notes: Data are presented as mean \pm SD for normally distributed data, median $(Q 75, Q 25)$ for skewed data 


\section{Table 3 (on next page)}

Stepwise Multiple Regression Model with 3MS as the Dependent Variable 
1

\begin{tabular}{|c|c|c|c|c|c|}
\hline Variable & $\begin{array}{c}\text { Unstandardized } \\
\text { Coefficient (B) }\end{array}$ & SE & 95\% CI & $\begin{array}{c}\text { Standardized } \\
\text { Coefficient ( } \beta)\end{array}$ & p-Value \\
\hline Intercept & 52.338 & 29.583 & & & 0.080 \\
\hline White & 23.902 & 4.559 & 14.837 to 32.967 & 0.460 & $<0.001$ \\
\hline Age & -0.760 & 0.264 & -1.285 to -0.234 & -0.279 & 0.005 \\
\hline $\begin{array}{c}\text { 6MWT } \\
\text { HR }\end{array}$ & 0.306 & 0.125 & 0.056 to 0.555 & 0.238 & 0.017 \\
\hline
\end{tabular}

Note: Modified Mini-Mental State Test (3MS); 3MS is rank transformed prior to model fitting; SE 3 Standard Error; 95\% CI - 95\% Confidence Intervals for the coefficients; Peak heart rate recorded 4 during the 6-Minute Walk Test (6MWT HR peak $)$ 5 


\section{Table 4(on next page)}

Stepwise Multiple Regression Model with Animal Naming as the Dependent Variable 
1

\begin{tabular}{|c|c|c|c|c|c|}
\hline Variable & $\begin{array}{c}\text { Unstandardized } \\
\text { Coefficient (B) }\end{array}$ & SE & 95\% CI & $\begin{array}{c}\text { Standardized } \\
\text { Coefficient ( } \beta)\end{array}$ & p-Value \\
\hline Intercept & 14.400 & 0.940 & & & $<0.001$ \\
\hline Asian & -3.044 & 0.902 & -4.837 to -1.250 & -0.304 & 0.001 \\
\hline PASE & 0.015 & 0.005 & 0.006 to 0.024 & 0.299 & 0.001 \\
\hline Education & 2.082 & 0.746 & 0.599 to 3.565 & 0.260 & 0.006 \\
\hline $\boldsymbol{\beta}$-blocker & -2.069 & 0.964 & -3.986 to -0.152 & -0.198 & 0.035 \\
\hline
\end{tabular}

2Note: SE - Standard Error; 95\% CI - 95\% Confidence Intervals for the coefficients; Physical 3 Activity Scale for the Elderly (PASE)

4 


\section{Table 5 (on next page)}

Stepwise Multiple Regression Model with TMT A as the Dependent Variable 
1

\begin{tabular}{|c|c|c|c|c|c|}
\hline Variable & $\begin{array}{c}\text { Unstandardized } \\
\text { Coefficient (B) }\end{array}$ & SE & 95\% CI & $\begin{array}{c}\text { Standardized } \\
\text { coefficient ( } \beta \text { ) }\end{array}$ & p-Value \\
\hline Intercept & 3.608 & 0.543 & & & $<0.001$ \\
\hline $\begin{array}{c}\text { 6MWT } \\
\text { HR }\end{array}$ & -0.005 & 0.002 & -0.012 to -0.003 & -0.214 & $<0.001$ \\
\hline PASE & -0.005 & 0.001 & -0.002 to 0.00 & -0.226 & 0.017 \\
\hline Age & 0.011 & 0.005 & 0.001 to 0.020 & 0.234 & 0.031 \\
\hline
\end{tabular}

Note: TMTA- Trailmaking Test A; TMT A is lognormal distributed. A log transformation was 3 taken prior to model fitting; SE - Standard Error; 95\% CI - 95\% Confidence Intervals for the 4 coefficients; Peak heart rate recorded during the 6-Minute Walk Test (6MWT HR peak $)$ 5 
Table 6(on next page)

Stepwise Multiple Regression Model with TMT B as the Dependent Variable 
1

\begin{tabular}{|c|c|c|c|c|c|}
\hline Variable & $\begin{array}{c}\text { Unstandardized } \\
\text { Coefficient (B) }\end{array}$ & SE & $\mathbf{9 5 \%}$ CI & $\begin{array}{c}\text { Standardized } \\
\text { coefficient }(\boldsymbol{\beta})\end{array}$ & p-Value \\
\hline Intercept & 4.426 & 0.605 & & & $<0.001$ \\
\hline $\begin{array}{c}\text { 6MWT } \\
\text { HR }\end{array}$ & -0.006 & 0.003 & -0.011 to -0.001 & -0.236 & 0.029 \\
\hline $\begin{array}{c}\text { Education } \\
\text { Age }\end{array}$ & -0.250 & 0.098 & -0.444 to -0.056 & -0.254 & 0.012 \\
\hline 0.011 & 0.006 & 0.000 to 0.022 & 0.210 & 0.049 \\
\hline
\end{tabular}

2Note: Trailmaking Test B (TMT B); TMT B is lognormal distributed. A log transformation was 3 taken prior to model fitting; SE - Standard Error; 95\% CI - 95\% Confidence Intervals for the

4 coefficients; Peak heart rate recorded during the 6-Minute Walk Test (6MWT HR peak $)$ 